\title{
Outcomes of Medical Education in Nepal
}

\author{
Reddy VD ${ }^{*}$, Upadhayay $N^{2}$, Yadav $\mathrm{SK}^{2}$, Subedi B ${ }^{2}$ \\ 'Professor \& HOD, '2Lecturer, Department of Physiology, \\ Gandaki Medical College \& Teaching Hospital, Pokhara, Nepal
}

\author{
Keywords \\ Medical education, Medical students, \\ Medical teachers.
Corresponding author
*Dr. V. Devendar Reddy
Professor \& Head, Department of
Physiology
Gandaki Medical College \&Teaching
Hospital, Pokhara, Nepal \\ Email: reddysir4861@gmail.com
}

\begin{abstract}
The standards of medical education in Nepal and other countries in Asia are improving gradually. The medical education is appeared to be student centered. But a teacher is also responsible to improve the academic standards and overall performance of the students. There is a need to provide short period of practical vocational training to teachers in the subject of their specialty. A better teacher trains the student in a better way than untrained medical personnel. In any class, the students are the best judges, so teachers should get a feedback from students after the class and it leads to better performance by a teacher in future classes.
\end{abstract}

Medical education in Nepal is improving like in India. There is a large scale expansion in medical educational institutions; but the quality of medical graduates is in question. There is a great need to rectify the deficiencies of medical education system.

There is a change taking place in the curricula of various universities where the instruction is student centered. Faculty qualification requirement is needed; the teachers do not have any practical exposure. In the process, the medical students are receiving training in textual material only in medical graduation. There is a need of practical training to teachers and lab technicians in the subject of their expertise. This will improve the situation because the teachers can teach with practical orientation.

The way, we examine and evaluate the utilization of financial, physical and human resources; the teaching learning process, research output, paper presentation, seminars are to be provided to students for evaluation. Success rate in academics are considered and in the process overall improvement of institution is ensured.

The student is expected to attain necessary practical expertise and this knowledge can be utilized in clinical side. A student must develop the various competencies for the time of his/her graduation. The five broad categories are

1. The ability to apply knowledge of medicine

2. An ability to design and conduct experiments

3. An understanding of professional and ethical responsibility in dealing with patients

4. An ability to communicate effectively

5. An ability to engage in lifelong learning by utilizing recent advances in medical science

The educational objectives of MBBS program are broadly for preparation of the student to succeed in medical profession or in higher education to acquire competencies and the breadth of knowledge that a student must possess in his branch of medical speciality, so that a student can comprehend, analyze his medical knowledge. Professionalism has to be inculcated in the student with ethical values and effective communication skills.

Still even now the medical education is better than other non-medical institutions. In medical education the students undergo practical training right from their first year to final year and they undergo one full year of internship at the end of graduation. The teachers are 
practicing doctors and eventually these fresh medical graduates are able to earn their livelihood soon after their graduation. The better part of program educational objective is that students get exposure to the community field from the first year to the final year which make them (students) to learn the real situation of the condition. This will help students after graduation to treat those people since they are already having some knowledge. Now the medical graduates are not confined to urban area. They get necessary confidence to treat patients. The best solution to improve further into medical education is to train one faculty by experienced teachers in the subject areas which they are going to teach during subsequent semesters. This should be made compulsory and they are to be provided incentives in the lines of paper presentations. One should not forget the importance of class attendance and attention of students in the class rooms. A student who attends the classes regularly; his/her academic performance definitely improves when compared to the student who is irregular to the classes ${ }^{1,2}$. But we shouldn't forget to improve the quality of students enrolling in medical education. We can improve this by taking the standard proven methods of entrance examination and enrolment in merit basis.

The effective use of audiovisual teaching aids by a teacher improves better understanding of subject even by a below average students. Planning, preparing and using audiovisual teaching aids has an impact in understanding the topic of a subject. Visual perception contributes to about $90 \%$ to all human learning. Maximum attention of an adult learner is 40 minutes to sustain attention and interest. Various other stimuli are necessary like asking questions in between, and followed by continuation of lecture. Audiovisual aids will lead to more number of senses used by learner. Explaining and presentation is more effective than only explaining or only presentation. Some thoughts on methodology of using power point presentation are that $90 \%$ of information going to brain is through vision, $8 \%$ of information going to brain is through hearing, and $2 \%$ of information is going to brain through other senses.
One time writing is equal to few times reading. So a student in the class has to write the notes while teacher is taking the class, so that students can remember the subject for longer periods. So ask the student to write the notes. However some below average students may be indulging in copying what has been shown in the power point and may not listen promptly to teacher's explanations in the classroom. In that situation, many important parts may be missed out. Therefore a short note or hands out of the presented topic should be provided to the students at the end of class but before providing short notes or handout, students must be ensured that these notes are only the guidelines not the entire topic because we can't confine medical science in notes, handouts, or even entire book.

A teacher mindset before going to the class should be in such a way that he/she can be capable of handling the class as a well experienced and more knowledgeable person than a student. A teacher should not under estimate himself/herself before going to class room. Practice of teaching and getting feedback from students' leads to effective class room teaching; along with taking feedback with colleagues, subject experts from time to time will be beneficial in improving teacher's skills and helps them to build confidence in that particular topic too.

Two important persons in the medical education is a teacher and a learner that is the students. Teaching ultimately improves teacher's skills, knowledge and is also in turn beneficial to the students. At the end what I wish to express that we have to work hard to improve the standards of medical education.

\section{REFERENCES}

1. Robert M. Schmidt. "Who maximizes what? A study in student time allocation". American Economic Review. May 1983; 23-28.

2. Kang H, Park and Peter M. Kerr: "Determinants of academic performance: A multinomial logit approach". The Journal of Economic Education. Spring, 1990; 101-111. 